\title{
Job preferences among clinical officers in public sector facilities in rural Kenya: a discrete choice experiment
}

\author{
Toshio Takemura $^{1 *}$, Karina Kielmann ${ }^{1}$ and Duane Blaauw ${ }^{2}$
}

\begin{abstract}
Background: Clinical officers (COs), a mid-level cadre of health worker, are the backbone of healthcare provision in rural Kenya. However, the vacancy rate for COs in rural primary healthcare facilities is high. Little is known about factors motivating COs' preferences for rural postings.

Methods: A discrete choice experiment (DCE) questionnaire was used with 57 COs at public health facilities in nine districts of Nyanza Province, Kenya. The questionnaire was developed on the basis of formative qualitative interviews with $\operatorname{COs}(n=5)$ and examined how five selected job attributes influenced COs' preferences for working in rural areas. Conditional logit models were employed to examine the relative importance of different job attributes.

Results: Analysis of the qualitative data revealed five important job attributes influencing COs' preferences: quality of the facility, educational opportunities, housing, monthly salary and promotion. Analysis of the DCE indicated that a 1-year guaranteed study leave after 3 years of service would have the greatest impact on retention, followed by good quality health facility infrastructure and equipment and a 30\% salary increase. Sub-group analysis shows that younger COs demonstrated a significantly stronger preference for study leave than older COs. Female COs placed significantly higher value on promotion than male COs.

Conclusions: Although both financial incentives and non-financial incentives were effective in motivating COs to stay in post, the study leave intervention was shown to have the strongest impact on COs' retention in our study. Further research is required to examine appropriate interventions at each career stage that might boost COs' professional identity and status but without leading to larger deficits in the availability of generalist COs.
\end{abstract}

Keywords: Mid-level workers, Clinical officers, Job preferences, Retention, Discrete choice experiment, Kenya

\section{Background}

The World Health Organization (WHO) recommends the utilization of mid-level workers (MLWs) to increase access to health workers in rural areas [1]. Since their training period is relatively short, and their remuneration is lower than that of physicians, MLWs are seen to be more financially advantageous in resource-limited settings [2]. In fact, 25 of 47 countries in sub-Saharan African countries have introduced MLWs who take on many of the functions of medical doctors especially in

\footnotetext{
* Correspondence: ttoshioster@gmail.com

'Institute for Global Health and Development, Queen Margaret University,

Edinburgh EH21 6UU, UK

Full list of author information is available at the end of the article
}

poorly served regions [2]. In Kenya, for example, clinical officers (COs) make up 6\% of the total health workforce. While they function as the backbone of healthcare provision especially in rural areas [3], many COs express dissatisfaction with their jobs due to low remuneration, poor career progress and limited educational opportunities especially in rural areas [4] which has impacted on rural retention and attraction. For example, a recent workload analysis among doctors, nurses and COs in Kenya indicates the severe shortage of COs at rural facilities [5].

Although there are published guidelines suggesting policies to address health worker attraction and retention in remote and rural areas [1], the evidence base for 
effective strategies and interventions to promote retention of health workers in low- and middle-income countries is relatively weak $[1,6]$. Discrete choice experiments (DCEs) have been put forward as one promising methodology to explore these issues in developing countries [7]. A DCE is a quantitative method used to assess individuals' relative valuation of attributes by requesting them to make choices from a set of different hypothetical alternatives [8]. According to a DCE guide by WHO, the World Bank and USAID [9], the tool can be used to investigate the impact of factors that influence retention of the health workforce in rural areas. The method allows researchers to estimate the strength of preferences for specific job attributes [10].

While many studies have examined factors for health worker retention in remote areas [11], most existing research has focused on physicians and nurses. Several studies on MLWs have assessed their performance as non-physician clinicians [12, 13], but there are few studies that examine the retention of MLWs [14]. This is the first study to our knowledge that uses the DCE methodology to explore job preferences of in-service COs, a critically important cadre in the health workforce of many African countries including Kenya.

Kenya is 1 of 57 countries deemed to have a human resources for health (HRH) crisis [15]: a 2010 report indicates the density of doctors, nurses and midwives to be just 1.44 per 1000 population, far below the WHO minimum requirement for service delivery [16]. The Government of Kenya (GOK) has realized that the shortage of human resources is a bottleneck to the expansion of priority health services including those addressing the burden of HIV/AIDS, TB and malaria [17].

Kenya has been facing the challenges of attraction and retention of health workers in rural areas. A verification exercise in 2004 revealed that more than half of health workers are working in urban areas while approximately $80 \%$ of the Kenyan population live in rural regions [18]. According to the GOK Human Resources for Health Strategic Plan 2009-2012, which outlines options to retain specific target cadres and develop retention packages, "...the retention problem is particularly acute in remote/hard-to-reach areas" [3, p. xiii].

COs complement doctors and support curative, preventive, promotive and rehabilitative services [19]. In 2012, there were 2167 COs posted in public sector facilities in Kenya, which is almost twice as many as physicians [20]. The Kenyan CO cadre comprises two sub-groups: general COs (registered clinical officers, RCOs) and specialist COs (SCOs; COs with further specialist training in one medical discipline) [21]. While GOK estimates that 9827 RCOs and 1229 SCOs are required by 2017, existing numbers were 1246 and 921, respectively, as of 2012 [20]. Although some COs are in charge of health centres in rural areas [3], the distribution of COs is highly skewed toward district hospitals [18]. The vacancy rate for COs in the primary healthcare level is higher than that of doctors or nurses [16], partly because attrition rates of $\mathrm{COs}$ in health centres are greater than in district hospitals [17]. However, little is known about COs' job preferences for working in rural areas.

\section{Methods}

\section{Study setting and respondents}

This research was conducted in Nyanza Province, in the western part of Kenya (Fig. 1). The province has some of the poorest health indicators in the country with an HIV prevalence of $14.9 \%$ and an infant mortality of 95 per 1000 [22, 23]. Table 1 presents socio-demographic and health access characteristics of the selected study districts. Nyanza Province has a relatively high proportion of COs (14\% of total COs in the public sector) [16].

\section{Sampling}

We employed a multistage stratified cluster sampling strategy. Nine districts out of 39 were purposively selected for two reasons: (1) they were predominantly rural according to the 2009 census [22] and (2) they included various ethnic groups in Nyanza Province. Within the districts, all public health facilities that had at least one $\mathrm{CO}$ were selected $(n=31$ out of 121 in Nyanza Province). All COs were subsequently invited to participate in the study. Although several studies suggest that sample size calculation for DCE depends on survey design and statistical model [24], sampling guidelines for DCE remain poorly defined [25]. Based on a previous study with a sample size of 50 pharmacy students [26], we aimed to obtain questionnaires from 50 COs. Given a $10 \%$ refusal rate or possible missing data, the required sample size for the DCE was increased to 55 . We sought to survey all COs present in each facility surveyed on the day of the visit during June and July 2013.

\section{Instrument development}

The first stage of developing a DCE tool involves identifying attributes relevant to the research question and then determining the levels of these attributes [9]. In this study, DCE attributes and levels were determined by three activities: (1) consulting other studies including those on health workers' motivation, retention, MLWs, similar DCEs and the WHO 2010 recommendations; (2) semi-structured interviews with purposively selected COs from four districts $(n=5)$; and (3) pre-testing of the instrument with COs from one district $(n=3)$. We modified a semi-structured interview guide by Jaskiewicz and colleagues [10], which contains a range of questions about working conditions in rural regions. The aims of 


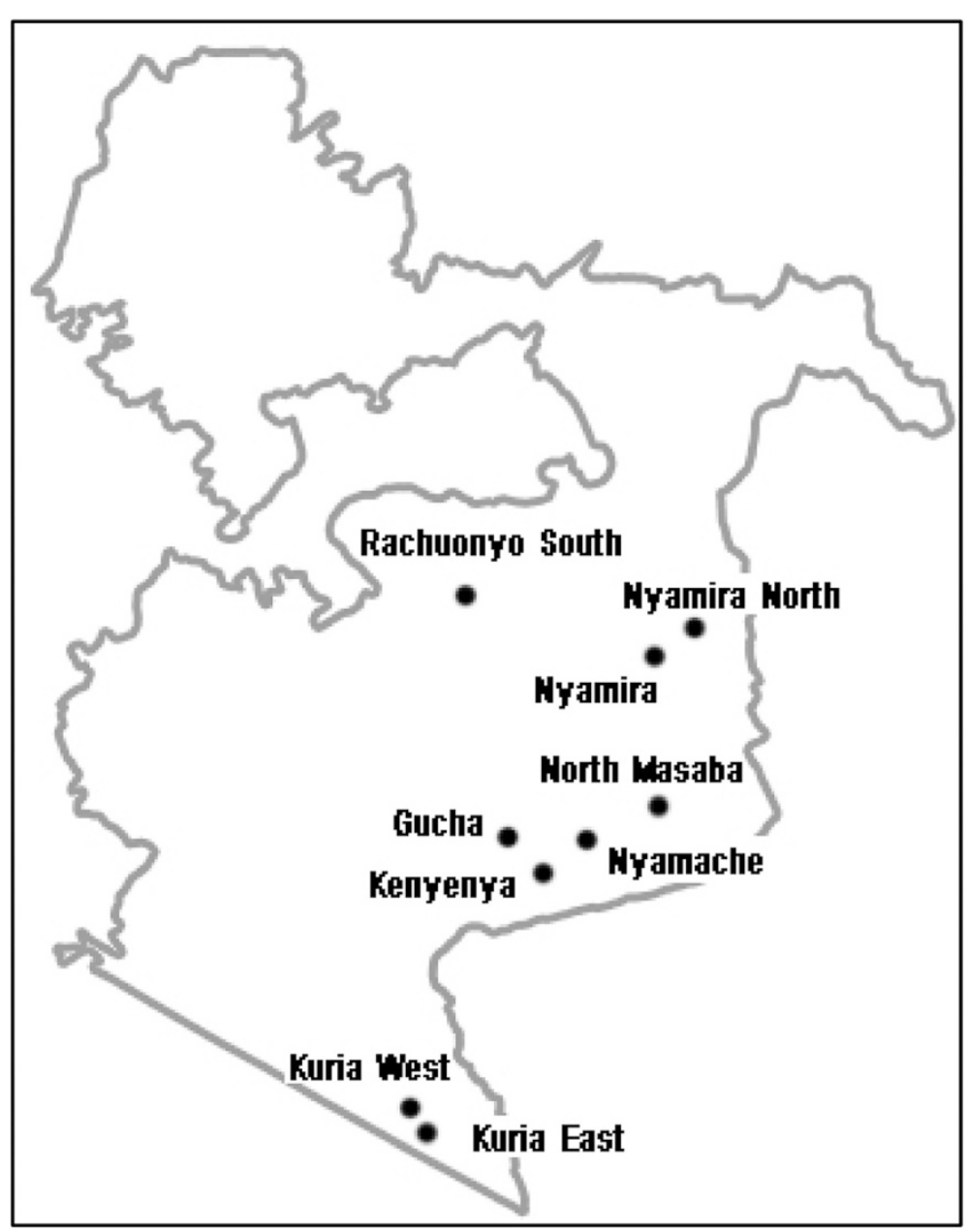

Fig. 1 Map of Nyanza Province

Table 1 Socio-demographic characteristics and health access in the nine districts

\begin{tabular}{|c|c|c|c|c|c|c|}
\hline District & $\begin{array}{l}\text { Major ethnic } \\
\text { group }\end{array}$ & $\begin{array}{l}\text { Rural/urban } \\
\text { proportion ratio }\end{array}$ & $\begin{array}{l}\text { No of deployed } \\
\operatorname{COs}^{\mathrm{b}}\end{array}$ & $\begin{array}{l}\text { No of district } \\
\text { hospitals }^{c}\end{array}$ & $\begin{array}{l}\text { No of sub-district } \\
\text { hospitalsc }^{c}\end{array}$ & $\begin{array}{l}\text { No of health } \\
\text { centres }^{c}\end{array}$ \\
\hline Rachuonyo South & Luo & 1.9 & 13 & 1 & 1 & 2 \\
\hline Gucha & Kisii & 16.3 & 9 & 1 & 0 & 0 \\
\hline Kenyenya & Kisii & 16.3 & 5 & 1 & 0 & 0 \\
\hline Nyamache & Kisii & 16.3 & 5 & 0 & 2 & 1 \\
\hline Nyamira & Kisii & 3.3 & 16 & 1 & 0 & 14 \\
\hline Nyamira North & Kisii & 3.3 & 5 & 0 & 2 & 8 \\
\hline North Masaba & Kisii & 1.9 & 13 & 1 & 1 & 2 \\
\hline Kuria West & Kuria & 7.5 & 12 & 1 & 1 & 7 \\
\hline Kuria East & Kuria & 7.5 & 7 & 1 & 1 & 1 \\
\hline
\end{tabular}

Source: $[22,45]$

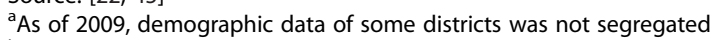

${ }^{\mathrm{b}}$ This information was provided directly by district officials

${ }^{c}$ Facilities owned by Ministry of Health are represented. Sub-district hospital is a general health facility, staffed by clinical officers and a few health practitioners [4] 
the interviews were twofold: (1) to obtain detailed information on COs' job preference and (2) to identify attributes and levels for a DCE study. A total of five COs from four districts were interviewed. The interview data helped to identify the following five locally meaningful job attributes (with the related WHO [1] intervention category shown in brackets): quality of facility (professional and personal support), educational opportunities (education), housing (professional and personal support, financial incentives), monthly salary (financial incentives), and promotion (professional and personal support, financial incentives). Table 2 summarizes the final attributes and their levels used in this study.

The number of possible job posting scenarios depends on the number of attributes and levels. Although we used a generic design for DCE, in which the job postings were not labelled as rural or urban, respondents were

Table 2 DCE attributes and levels for COs in Kenya, 2013

\begin{tabular}{cl}
\hline Attribute 1 & Quality of facility \\
Level 1 & $\begin{array}{l}\text { Basic (e.g. unreliable electricity, equipment and } \\
\text { drugs and supplies not always available) }\end{array}$ \\
Level 2 & $\begin{array}{l}\text { Advanced (e.g. reliable electricity, equipment and } \\
\text { drugs and supplies always available) }\end{array}$ \\
Attribute 2 & Education opportunity \\
Level 1 & No guaranteed study leave \\
Level 2 & 1-year guaranteed study leave after 5 years of service \\
Level 3 & 1-year guaranteed study leave after 3 years of service \\
Attribute 3 & Housing \\
Level 1 & Small amount of house allowance provided, but not \\
enough to afford basic housing
\end{tabular}

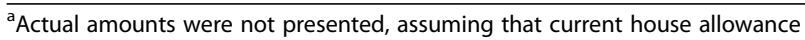
was not enough as mentioned by COs in the interviews

${ }^{\mathrm{b}}$ Detailed information on basic and superior housing with participants was not provided

'As of 2013, entry-level COs received monthly basic salaries of KES 19323 (USD 221) converted at a rate of (USD $1=$ KES 87.31). Although monthly salary levels are different among and within $\mathrm{CO}^{\prime}$ job groups, there was no area difference because the monthly salary attribute in the questionnaire was described as not including allowances

dFollowing the another DCE study in Kenya [27], levels of monthly basic salary in the DCE instruments were set requested to assume that they were looking for a new job and to choose between two advertised job postings in government health facilities in rural areas. As described in Table 2, there was one attribute with four levels, two attributes with three levels and two attributes with two levels in this study. This design generated $144\left(4^{1} \times 3^{2} \times 2^{2}\right)$ possible scenarios with different combinations of levels of the five job attributes. To reduce the number of choices, an experimental design was selected using Sawtooth Software's Choice-Based Conjoint module (Sawtooth Software, Inc., USA). The software helps to develop DCE questionnaires that maximize level balance (inclusion of attribute levels in similar proportions) and orthogonality (minimal correlation between different attribute levels) and minimize overlap between attribute levels within one task $[9,27]$. Following Jaskiewicz and colleagues [10], we used Sawtooth to generate five different versions of the questionnaire in order to improve design efficiency. Each version had 12 choice tasks with a different combination of attribute levels.

\section{Data collection}

All respondents randomly received one version and were asked to select one of the two job scenarios from each choice task, as shown in Fig. 2. Questionnaires did not include the option of not choosing any of the alternatives. The rationale for employing a forced choice is that although an opt-out option can reduce biases in parameter estimates, it cannot provide sufficient information on respondents' preferences for the attributes if many respondents choose the opt-out option [9].

The DCE tool included questions on respondents' demographic characteristics and professional background. The DCE survey was conducted in English as this is the language of instruction in $\mathrm{CO}$ training schools. Paperbased questionnaires were administered to COs individually at their workplace during work hours. Although the researcher sought to survey all COs present in each facility on the day of the visit, some COs were not available due to their work shifts, training, maternity leave or annual leave. However, available COs were eager to participate in the survey, and no one declined. Respondents were allowed to answer at their own pace and under the researcher's direct supervision. The survey took around 10 to $20 \mathrm{~min}$ to complete.

\section{Data analysis}

The five qualitative interviews were transcribed into MS Word 2010 (Microsoft Corporation, USA). Themes emerging in relation to the overall topic of preferred job attributes were identified in a threefold manner: (1) reading the transcripts and making notes on relevant issues in the margins of the interview transcript, (2) listing out these comments in separate files and grouping them 


\begin{tabular}{|c|c|c|}
\hline Attribute & Job Posting A & Job Posting B \\
\hline $\begin{array}{l}\text { Quality of the } \\
\text { facility }\end{array}$ & $\begin{array}{l}\text { Advanced (e.g. reliable electricity, } \\
\text { equipment and drugs and supplies } \\
\text { always available) }\end{array}$ & $\begin{array}{l}\text { Basic (e.g. unreliable electricity, } \\
\text { equipment and drugs and supplies } \\
\text { not always available) }\end{array}$ \\
\hline $\begin{array}{l}\text { Education } \\
\text { opportunities }\end{array}$ & $\begin{array}{l}1 \text {-year guaranteed study leave after } \\
5 \text { years of service }\end{array}$ & $\begin{array}{l}\text { 1-year guaranteed study leave after } \\
3 \text { years of service }\end{array}$ \\
\hline Housing & $\begin{array}{l}\text { House allowance provided, but not } \\
\text { enough to afford basic housing }\end{array}$ & $\begin{array}{l}\text { House allowance provided, } \\
\text { enough to afford superior housing }\end{array}$ \\
\hline $\begin{array}{l}\text { Monthly basic } \\
\text { salary (not } \\
\text { including } \\
\text { allowances) }\end{array}$ & $\begin{array}{l}10 \% \text { additional monthly basic } \\
\text { salary }\end{array}$ & $\begin{array}{l}30 \% \text { additional monthly basic } \\
\text { salary }\end{array}$ \\
\hline \multirow[t]{2}{*}{$\begin{array}{l}\text { Promotion(number } \\
\text { of years to be spent } \\
\text { in the facility until } \\
\text { being eligible for } \\
\text { promotion) }\end{array}$} & 3 years & 2 years \\
\hline & $\square$ & $\square$ \\
\hline
\end{tabular}

Fig. 2 Example of choice set. Which of these two job postings do you prefer? Select one by ticking the box under the job you prefer

thematically and (3) selecting the most relevant themes, based on how commonly and strongly they were expressed by the respondents.

All data from the DCE questionnaires was entered and stored using Microsoft Excel 2010 (Microsoft Corporation, USA). Following this, the conditional logit (CL) model was used to analyse job preference using Stata/IC 12 module (Stata Corporation, USA). McFadden's CL [28] is based on random utility theory where the decision maker $n$ is assumed to be a rational economic individual, facing a choice among $J$ alternative jobs. The individual will choose alternative job $i$ over alternative job $j$ if and only if $U_{n i} \geq U_{n j}$. The utility is not directly observable, and therefore, the model assumes that the utility function consists of two components:

$$
U_{i}=V_{i n}+\varepsilon_{i n}
$$

The researcher can observe $V_{i n}$ while $\varepsilon_{i n}$ is unobservable and treated as a random component. Allowing $V_{i n}=\beta x_{n i}$, where $\beta x_{n i}$ is a matrix of job attributes, the probability of choosing job $i$ from $J$ alternative jobs can be parametrized as the logit formula [29]:

$$
P_{n i}=\frac{e^{\beta x_{n i}}}{\sum_{j} e^{\beta x_{n j}}}
$$

A CL model is obtained by assuming that the random error component is independent, identically distributed and follows the extreme value distribution [29]. Categorical variables were entered as dummy variables while salary was treated as a continuous variable. Subgroup analysis was conducted by including interaction terms between demographic variables and job attributes (salary * gender, for example). Demographic characteristics do not vary within choice sets and cannot be added into the CL regression model directly [9]. Models were run with and without the demographic interaction variables for comparison.

We also calculated willingness to pay (WTP) estimates and confidence intervals by dividing attribute coefficients by the continuous salary coefficient. WTP is useful because it can inform policymakers of the pricing of goods or services by providing information on to what extent people value them [30]. In this study, WTP refers a willingness to give up salary for an improvement in other attributes of a job.

In addition to the CL models for main effect and interactions, we further analysed the data using mixed logit models with Hole's mixlogit command for Stata [31]. We ran two mixed logit (MXL) models: (i) with the salary attribute as fixed and (ii) with the salary attribute as random and lognormal. In both models, all other attributes were treated as random components following a lognormal distribution because the direction of the attribute valuation was clear from the DCE design [29]. Although some studies suggest that MXL models have advantages over standard logit models in terms of flexibility, reduction of standard error and inclusion of demographic characteristics [29], the MXL model requires a larger sample size than the CL model [25]. In this study, the results from each MXL model were not substantially different from the CL model. Given our small sample size, the main analysis applied in this study was using the CL model.

\section{Ethical considerations}

Ethical approval was obtained from Queen Margaret University, and the study was undertaken with permission from the Provincial Director of Public Health and Sanitation Services, Nyanza Province. Written informed consent was taken from all the participants 
who were informed about the research and their voluntary participation.

\section{Results \\ COs' preferred job attributes: insights from qualitative interviews}

Remuneration of Kenyan COs consists of basic salary, housing allowance, commuter allowance, health risk allowance and extraneous allowance. The basic monthly salary for a first-year CO is KES 19323 (USD 221) as of 2013, and a hardship allowance is provided when they work in designated areas. For the five COs interviewed, critical factors relating to job preferences included salary and allowance issues but also the state of the facility, educational opportunities and possibilities for promotion.

Some COs directly mentioned the need for financial incentives in rural areas, "...so as to bring people who are working in towns to come and assist in the village." [CO3]. Other respondents considered a salary increase in rural regions as compensation for a heavy workload. COs at remote facilities reported that they had to work longer due to the shortage of health workers as opposed to urban facilities which were better staffed.

Many respondents found housing conditions in rural and remote areas discouraging. While staff accommodation was available within some health facilities, the COs interviewed were not happy with the quality of housing. Although the GOK provides a housing allowance according to job group and location, COs were not satisfied with the amount, as expressed by a female $\mathrm{CO}$ based at the district hospital:

We get KES 2,300 (USD 26) [...] That is too little.... As house allowance, [there should be] at least KES seven to ten [thousand] (USD 80 to 114). [CO1]

In addition to allowances, respondents suggested that the state of the facilities in rural areas was often lacking. They mentioned in particular the lack of equipment, shortage of drug supplies and poor infrastructure at both the district hospital and health centre level. As a result of these gaps, COs working in remote areas reported that they had to refer clients to urban hospitals even if they could manage the patients.

Health workers including COs who meet certain requirements are granted paid study leave [32]. Respondents, however, stated limited opportunities for continuous education in rural facilities; as one male $\mathrm{CO}$ in a health centre lamented:

They (government) are saying we do not have enough staff, so at the end of the day, you find yourself working throughout. You do not have time to study. [CO5]
Others pointed out the long process required to apply for study leave and the lack of tuition support for further education.

Some respondents mentioned the lack of promotion opportunities, especially in rural areas. One female CO based at the district hospital directly questioned the promotion system:

You are supposed to be promoted every three years, but now, you can fill the performance contracts forms yearly, but you still don't get promoted even seven to ten years $[\mathrm{CO} 1]$

Relative importance of job attributes: results from the DCE Out of 85 public COs deployed in the study districts, 57 (67\%) COs participated in the survey. The figure corresponds to $16 \%$ of COs $(n=356)$ in Nyanza Province. Details are shown in Table 3. Descriptive statistics on the demographic and professional background of COs are provided in Table 4. Sixty percent of COs surveyed was male, which was almost the same as the national level [20]. The mean age of COs was 33.0 years with a standard deviation of 7.6 years, which followed the age distribution at the national level. Around two thirds of COs were in the entry-level job group.

Table 5 presents the regression results for all models. The output from the CL model of the DCE job scenario data is shown in model 1 . The coefficients $(\beta)$ indicate the direction and relative importance of the attributes on utility [9]. The coefficient for salary, a continuous valuable, indicates the utility gained per $10 \%$ increase above the basic monthly salary for a $\mathrm{CO}$ in their first year of service. In model 1, all attributes were statistically significant. COs had high preference for a 1-year guaranteed study leave after 3 years of service $(\beta=2.23$, $P<0.01)$ and a 1 -year guaranteed study leave after 5 years

Table 3 Comparison of deployed COs and participant COs

\begin{tabular}{llll}
\hline District & $\begin{array}{l}\text { No of } \\
\text { deployed COs }\end{array}$ & $\begin{array}{l}\text { No of } \\
\text { participant COs }\end{array}$ & Rate (\%) \\
\hline Rachuonyo South & 13 & 8 & 62 \\
Gucha & 9 & 6 & 67 \\
Kenyenya & 5 & 3 & 60 \\
Nyamache & 5 & 3 & 60 \\
Nyamira & 16 & 9 & 56 \\
Nyamira North & 5 & 2 & 40 \\
North Masaba & 13 & 11 & 85 \\
Kuria West & 12 & 9 & 75 \\
Kuria East & 7 & 6 & 86 \\
Total & 85 & $57^{b}$ & 67 \\
\hline
\end{tabular}

${ }^{\mathrm{a}}$ Data provided by District Medical Office of Health or district hospital

${ }^{b}$ Corresponds to $16 \%$ of COs working at public sector in Nyanza Province $(n=356)$ as of 2009 [16] 
Table 4 Descriptive statistics of DCE participants

\begin{tabular}{|c|c|c|}
\hline & \multicolumn{2}{|c|}{$(N=57)$} \\
\hline & $n$ & $\%$ \\
\hline \multicolumn{3}{|l|}{ Demographic $^{a}$} \\
\hline Male & 34 & $60 \%$ \\
\hline Age mean $(S D)^{c}$ & 33.0 & 7.6 \\
\hline Currently married & 50 & $88 \%$ \\
\hline Has children & 48 & $84 \%$ \\
\hline Christian & 57 & $100 \%$ \\
\hline Lived in rural area at least 1 year & 48 & $84 \%$ \\
\hline \multicolumn{3}{|l|}{ Work experience } \\
\hline \multicolumn{3}{|l|}{ Facility type } \\
\hline District hospital & 26 & $46 \%$ \\
\hline Sub-district hospital & 14 & $25 \%$ \\
\hline Health centre & 13 & $23 \%$ \\
\hline District Medical Office of Health & 4 & $7 \%$ \\
\hline Employed by government & 49 & $86 \%$ \\
\hline Entry-level job group & 36 & $63 \%$ \\
\hline Years of work experience, mean (SD) & 7.3 & 6.1 \\
\hline Years of work at current facility, mean (SD) & 3.0 & 3.8 \\
\hline
\end{tabular}

of service $(\beta=1.64, P<0.01)$. Further, they preferred good quality health facility infrastructure and equipment to basic health facility infrastructure $(\beta=1.46, P<0.01)$, followed by superior $(\beta=1.00, P<0.01)$ and basic $(\beta=0.89, P<0.01)$ housing allowances and then a $10 \%$ salary increase $(\beta=0.39, P<0.01)$. COs had the least preference for rapid promotion $(\beta=0.34, P<0.05)$. The model suggests that a $40 \%(\beta=1.56)$ or $50 \%(\beta=1.95)$ salary increase would be required above the $\mathrm{CO}$ entry level to be comparable to other attributes.

CL model 2 includes age group and gender interaction terms which were statistically significant. The sub-group analysis indicates that younger age groups had a significantly higher preference for study leave after 3 years while COs aged 40 and above showed less preference for study leave after 5 years. Female COs had higher preference for rapid promotion. There were no significant differences for other attributes by age or gender.

Next, we turn to the results of the MXL in models 3 and 4. Although the results of both CL and MXL models show that a 1-year guaranteed study leave would have the greatest impact on retention, the MXL models suggest that COs would be more likely to choose a job offering a $30 \%$ salary increase $(\beta=1.77)$ than a job offering good quality health facility infrastructure and equipment $(\beta=1.37)$. The statistically significant standard deviations in MXL models indicate substantial heterogeneity in COs' preferences for salary increase, good quality health facility infrastructure and equipment, study leave after 3 years and basic housing allowance.

The results of the WTP calculation for all COs are shown in Table 6. Outputs from CL model 1 were used for WTP calculation because MXL models require larger sample size than available in this study [25] even though the MXL models had better fit than the CL models. The sample sizes for the sub-group analyses were also too small for valid WTP calculations. This analysis explains how much of an entry-level salary (KES 19323) COs were willing to forgo for another attribute. COs were most willing to sacrifice as much as KES 10990 in exchange for a 1-year guaranteed study leave after 3 years of service compared with a job posting with no guaranteed study leave. The overall WTP, calculated as a sum of WTPs, can compare retention packages [33]. For instance, if a job offers two incentives: (1) a 1-year guaranteed study leave after 3 years of service and (2) allowance for superior housing (WTP total: KES 15950), COs are likely to accept the job even if another job offers three incentives: (1) a 30\% salary increase, (2) good quality health facility infrastructure and equipment and (3) rapid promotion (WTP total: KES 14631).

\section{Discussion}

Our analysis provides some qualitative insights and quantitative estimates of the likely impact of interventions that aim to improve rural retention among Kenyan COs. The strongest preference was expressed for a 1year study leave. The Kenyan CO Council has pointed out the inadequate continuous professional development system for COs [34]. The appeal for continuous education has also been observed in the study for MLWs in Tanzania and Malawi [35, 36].

However, considering the resulting increase in workload for remaining staff, a 1-year study leave might be difficult to implement. Further, training interventions can have a negative impact on the supply of workforce. Since the demand for SCOs is not as great as that for RCO [20], further specialist training intervention might lead to the larger imbalance between supply and demand for general COs. Given the report that SCOs feel it is beneath their status to work in out-patient departments when deployed there to cover RCO shortages [21], this type of training intervention should be carefully examined.

A review paper on health worker's motivation and retention indicates that the improvement of hospital infrastructure and resource availability could increase retention [37]. In our DCE, improved facility quality was the second most important factor influencing COs' job preferences. This finding is in agreement with results of other DCE studies that show a strong 
Table 5 DCE regression results

\begin{tabular}{|c|c|c|c|c|c|c|}
\hline & & Model $1^{\text {a }}$ & Model $2^{\mathrm{a}}$ & & Model $3^{b}$ & Model $4^{b}$ \\
\hline Attribute & Parameter & $\mathrm{CL}$ & CL with interaction & Parameter & $M X L$ with salary fixed & MXL with salary random \\
\hline \multirow[t]{2}{*}{ Salary ${ }^{c}$ (per 10\% change above base) } & $\beta$ & $0.39^{* * *}$ & $0.40^{* * *}$ & Mean & $0.44^{* * *}$ & $0.59^{* * *}$ \\
\hline & & & & SD & - & $0.57^{* * *}$ \\
\hline \multirow[t]{2}{*}{ Good quality of facility } & $\beta$ & $1.46^{* * *}$ & $1.47^{* * *}$ & Mean & $1.04^{* * *}$ & $1.37^{* * *}$ \\
\hline & & & & SD & $0.77^{* * *}$ & $1.07^{* * *}$ \\
\hline \multirow[t]{2}{*}{ Study leave after 5 years } & $\beta$ & $1.64^{* * *}$ & $1.80^{* * *}$ & Mean & $1.42^{* * *}$ & $1.85^{* * *}$ \\
\hline & & & & SD & 0.35 & $0.66^{* *}$ \\
\hline \multirow[t]{2}{*}{ Study leave after 3 years } & $\beta$ & $2.23^{* * *}$ & $3.15^{* * *}$ & Mean & $2.11^{* * *}$ & $2.75^{* * *}$ \\
\hline & & & & SD & $0.83^{* * *}$ & $-1.21^{* * *}$ \\
\hline \multirow[t]{2}{*}{ Basic house allowance } & $\beta$ & $0.89^{* * *}$ & $0.90^{* * *}$ & Mean & $0.80^{* * *}$ & $1.01^{* * *}$ \\
\hline & & & & SD & 0.34 & $0.65^{* *}$ \\
\hline \multirow[t]{2}{*}{ Superior house allowance } & $\beta$ & $1.00^{* * *}$ & $1.02^{* * *}$ & Mean & $0.73^{* * *}$ & $0.95^{* * *}$ \\
\hline & & & & SD & 0.00 & $-0.38^{*}$ \\
\hline \multirow[t]{2}{*}{2 years for promotion } & $\beta$ & $0.34^{* *}$ & $0.40^{* * *}$ & Mean & $0.23^{* *}$ & $0.25^{*}$ \\
\hline & & & & SD & -0.04 & -0.25 \\
\hline \multicolumn{7}{|l|}{ Interaction terms } \\
\hline Study leave after 5 years $\times 40$ and above & & & $-0.82^{* *}$ & & & \\
\hline Study leave after 3 years $\times 30-39$ years old & & & $-1.04^{* * *}$ & & & \\
\hline Study leave after 3 years $\times 40$ and above & & & $-2.26^{* * *}$ & & & \\
\hline 2 years for promotion $\times$ female & & & $0.24^{*}$ & & & \\
\hline Constant & & -0.17 & -0.19 & & $-0.22^{*}$ & $-0.27^{*}$ \\
\hline \multicolumn{7}{|l|}{ Model diagnostics } \\
\hline Number of respondents & & 57 & 57 & & 57 & 57 \\
\hline Number of observations & & 1368 & 1368 & & 1368 & 1368 \\
\hline Log likelihood & & -637.0 & -621.0 & & -324.0 & -314.2 \\
\hline AIC & & 1290.0 & 1266.0 & & 676.1 & 658.5 \\
\hline $\mathrm{BIC}$ & & 1331.7 & 1328.7 & & 749.2 & 736.8 \\
\hline Prob $>\mathrm{chi}^{2}$ & & $<0.001$ & $<0.001$ & & 0.01 & $<0.001$ \\
\hline
\end{tabular}

Although married COs also showed less preference for study leave after 3 years, the result is omitted from the table because there is a correlation between marital status and age group

$C L$ conditional logit, $M X L$ mixed logit

$* P<0.10 ; * * P<0.05 ; * * P<0.01$

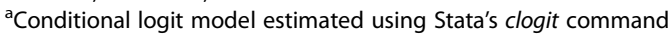

${ }^{\mathrm{b}}$ Mixed logit model estimated using Stata's mixlogit command [31]

'Base salary for COs in Kenya at the time of survey administration: KES 19323 per month (USD $1=$ KES 87.31)

Table 6 Willingness to pay estimates (KES)

\begin{tabular}{ll}
\hline & $\begin{array}{l}\text { Model } 1(\mathrm{CL}, \text { all }) \\
(N=57)\end{array}$ \\
\hline Good quality of facility & $7162(4876,9447)$ \\
Study leave after 5 years & $8064(5457,10670)$ \\
Study leave after 3 years & $10990(7699,14282)$ \\
Basic house allowance & $4372(2455,6289)$ \\
Superior house allowance & $4960(2937,6983)$ \\
2 years for promotion & $1672(344,3000)$ \\
\hline
\end{tabular}

Note: Base salary at the time of survey administration: KES 19323 per month (USD $1=$ KES 87.31). Numbers in parentheses are $95 \%$ confidence intervals. WTP and confidence intervals were estimated using Hole's wtp command in STATA [46] preference for the quality of the facility infrastructure or equipment [26, 37-39]. It also concurs with a motivation study in Kenya and Benin [40].

Salary was an important attribute but only at very high increases above the base level. A 30\% increase in salary would have the third highest coefficient. Furthermore, a $30 \%$ increase in salary was more preferred to improved facility quality in the MXL model. As salary level went up, the impact on rural retention for COs would increase. This finding concurs with the existing studies that underscore the importance of financial incentives for retention in rural regions [41]. Although the results suggest that COs would be highly responsive to a $30 \%$ 
salary increase, they would value housing allowance more than a $20 \%$ salary increase. This finding is consistent with previous studies that suggest that certain levels of salary would be required to improve retention [27, 39].

Housing allowances were also valued by COs. This contrasts with a study conducted in Tanzania, in which $\mathrm{CO}$ students did not attribute importance to housing [42]. Moreover, in other DCE studies, practising nurses have less preference for housing attributes than nursing students [27, 43]. Kenyan COs did not value accelerated promotion opportunities as highly as other attributes. This finding concurs with studies carried out with nursing students in Kenya, South Africa and Thailand [27]. Whereas our respondent COs had 7.3 work experience years on average, the majority $(63 \%)$ remained within the entry-level job group. This suggests that promotion mechanisms do not work effectively, at least in the study sites.

Younger COs showed a strong preference for education opportunities. This finding echoes the DCE conducted for student COs in Tanzania, revealing that COs are eager to gain more knowledge in the early stages of their career [42]. The results also suggest that reactions to incentives vary at the health worker's career stage [33].

Female COs were more likely to be responsive to promotion than male COs. However, there was no significant difference in other attributes. Existing studies show various consequences. While the DCE study in Tanzania for student COs found females more concerned with facility infrastructure [42], the multi-country DCE study for nurses showed that age and gender are not consistent predictors for choosing a rural post [27]. As there are differences across the studies, it appears important to take local context into account when developing retention strategies.

The sub-group analyses and MXL models suggested substantial heterogeneity among COs for the valuation of most attributes. This would indicate the difficulty of developing effective $\mathrm{HRH}$ interventions that apply to all COs. Policymakers could target interventions to different sub-groups of COs or at least consider the differential impact in their planning.

There are several limitations to this study. First, this research was conducted in only some districts in Nyanza Province, and therefore, the findings cannot be generalized to the whole country. Second, the DCE questionnaire in this paper provides only limited description of the attributes, and respondents may interpret these differently. Third, as with all stated preference studies, it is uncertain if respondents will actually select the stated choices. Other factors at various levels may affect the actual job choice decisions [37], and social desirability bias may lead to respondents choosing non-financial attributes rather than financial ones [27]. Lastly, the DCE did not include an opt-out option, which may result in biases in parameter estimates [9].

\section{Conclusions}

Although MLWs including COs are used in many developing countries, more sound evidence is required to gain a better understanding of their motivational factors for retention in rural regions [1]. In a DCE study of 57 Kenyan practising $\mathrm{COs}$, this paper presents data on job preferences. This study confirms that the bundles of intervention, both financial and non-financial, tailored to the local context are more efficient for rural retention than a single intervention [44]. Our study suggests that a study leave intervention would have the strongest impact on COs' retention in rural Kenya. However, preference for study leave seems to indicate a broader need to consider mechanisms for professional mobility, upgrading skills and status for COs. Further research is needed to examine interventions that can enhance their professional status without leading to a larger imbalance between supply and demand for COs.

\section{Abbreviations}

CO: clinical officer; DCE: discrete choice experiment; GOK: The Government of Kenya; HRH: human resources for health; MLWs: mid-level workers; RCO: registered CO; SCO: specialist CO; USAID: United States Agency for International Development; WHO: World Health Organization.

\section{Competing interests}

The authors declare that they have no competing interests.

\section{Authors' contributions}

$\Pi T$ carried out the study under supervision of KK. DB helped with the data analysis. $\Pi$ drafted the initial manuscript that was subsequently revised by KK and DB. All authors read and approved the final manuscript.

\section{Acknowledgements}

We would like to express deep gratitude to Dr. Tomohiko Sugishita-The Senior Advisor, Japan International Cooperation Agency-and Dr. Kioko Jackson-The Provincial Director of Public Health \& Sanitation services, Nyanza Province-for their permission and support. We also appreciate the District Health Management Teams for their assistance in coordinating data collection and the clinical officers who participated in this study.

\section{Author details}

${ }^{1}$ Institute for Global Health and Development, Queen Margaret University, Edinburgh EH21 6UU, UK. ${ }^{2}$ Centre for Health Policy/MRC Health Policy Research Group, School of Public Health, Faculty of Health Sciences, University of the Witwatersrand, Johannesburg, South Africa.

Received: 21 December 2014 Accepted: 22 December 2015 Published online: 08 January 2016

\section{References}

1. World Health Organization. Increasing access to health workers in remote and rural areas through improved retention. Geneva: World Health Organization; 2010.

2. Mullan F, Frehywot S. Non-physician clinicians in 47 sub-Saharan African countries. Lancet. 2007:370:2158-63.

3. Ministry of Medical Services, Ministry of Public Health and Sanitation. National human resources for health strategic plan (2009-2012). Nairobi, Kenya: Ministry of Medical Services; 2009.

4. Ndetei D, Khasakhala L, Omolo J: Incentives for health worker retention in Kenya: an assessment of current practice, Discussion Paper Series 62. Harare, Zimbabwe: EQUINET with African Mental Health Foundation, University of Namibia, Training and Research Support Centre, University of Limpopo and ECSA-Regional Health Community; 2008 
5. Ministry of Medical Services, Ministry of Public Health and Sanitation. The Nairobi Communique and Declaration of Commitment. In the First National Human Resources for Health (HRH) Conference in Kenya. Nairobi, Kenya: Ministry of Medical Services, Ministry of Public Health and Sanitation; 2012

6. Grobler L, Marais BJ, Mabunda SA, Marindi PN, Reuter H, Volmink J. Interventions for increasing the proportion of health professionals practising in rural and other underserved areas. Cochrane Database Syst Res. 2009;1: CD005.

7. Lagarde M, Blaauw D. A review of the application and contribution of discrete choice experiments to inform human resources policy interventions. Hum Resour Health. 2009;7:62.

8. Mangham LJ, Hanson K, McPake B. How to do (or not to do) ... designing a discrete choice experiment for application in a low-income country. Health Policy Plan. 2009;24:151-8

9. Ryan M, Kolstad J, Rockers PC, Dolea C. How to conduct a discrete choice experiment for health workforce recruitment and retention in remote and rural areas: a user's guide for policy makers and researchers. Geneva: World Health Organization, World Bank, and CapacityPlus; 2012.

10. Jaskiewicz W, Deussom R, Wurts L, Mgomella M. Rapid retention survey toolkit: designing evidence-based incentives for health workers. Washington, DC: CapacityPlus IntraHealth International; 2012. [http://www.capacityplus.org/files/resources/rapid_retention_survey\% 20_toolkit.pdf] (Accessed July 2 2015).

11. Dolea C, Stormont L, Braichet J. Evaluated strategies to increase attraction and retention of health workers in remote and rural areas. Bull World Health Organ. 2010;88:379-85.

12. Pereira C, Bugalho A, Bergström S, Vaz F, Cotiro M. A comparative study of caesarean deliveries by assistant medical officers and obstetricians in Mozambique. BJOG. 1996;103:508-12.

13. Chilopora G, Pereira C, Kamwendo F, Chimbiri A, Malunga E, Bergstrom S. Postoperative outcome of caesarean sections and other major emergency obstetric surgery by clinical officers and medical officers in Malawi. Hum Resour Health. 2007;5:17.

14. Lehmann U. Mid-level health workers: the state of the evidence on programmes, activities, costs and impact on health outcomes. Geneva: World Health Organization; 2008.

15. World Health Organization. World Health Report 2006: working together for health. Geneva: World Health Organization; 2006.

16. Ministry of Medical Services, Ministry of Public Health and Sanitation. National human resources for health annual report. Nairobi: Ministry of Medical Services, Ministry of Public Health and Sanitation; 2010

17. Chankova S, Muchiri S, Kombe G. Health workforce attrition in the public sector in Kenya: a look at the reasons. Hum Resour Health. 2009;7:58.

18. Ministry of Health. The report on human resource mapping and verification exercise. Nairobi, Kenya: Ministry of Health; 2005.

19. International Organization for Migration. Kenya mobility of health professionals. Brussels: International Organization for Migration; 2012.

20. Ministry of Medical Services, Ministry of Public Health and Sanitation. Transforming health: accelerating attainment of health goals, Kenya Health Sector Strategic \& Investment Plan (KHSSP) July 2012 - June 2017. Nairobi Kenya: Ministry of Medical Services and Ministry of Public Health and Sanitation; 2012

21. Mbindyo $P$, Blaauw D, English M. The role of clinical officers in the Kenyan health system: a question of perspective. Hum Resour Health. 2013;11:32.

22. Kenya National Bureau of Statistics and ICF Macro. Kenya demographic and health survey 2008-09. Calverton, Maryland: KNBS and ICF Macro; 2010. [http://dhsprogram.com/pubs/pdf/FR229/FR229.pdf] (Accessed July 2 2015).

23. Dillabaugh LL, Kulzer LJ, Owuor K, Ndege V, Oyanga A, Ngugi E, Shade SB, Bukusi E, Cohen CR: Towards elimination of mother-to-child transmission of HIV: the impact of a rapid results initiative in Nyanza Province, Kenya. AIDS Res Treat. 2012; 602120.

24. Rose J, Bliemer M. Sample size requirements for stated choice experiments. Transportation. 2013;40:1021-41.

25. de Bekker-Grob EW, Ryan M, Gerard K. Discrete choice experiments in health economics: a review of the literature. Health Econ. 2010;21:145-72.

26. Rockers PC, Jaskiewicz W, Wurts L, Kruk ME, Mgomella GS, Ntalazi F, et al. Preferences for working in rural clinics among trainee health professionals in Uganda: a discrete choice experiment. BMC Health Serv Res. 2012;12:212.

27. Blaauw D, Erasmus E, Pagaiya N, Tangcharoensathein V, Mullei $K$, Mudhune $S$, et al. Policy interventions that attract nurses to rural areas: a multicountry discrete choice experiment. Bull World Health Organ. 2010;88:350-6.
28. McFadden D. Conditional logit analysis of qualitative choice behavior. In: Zarembka P, editor. Frontiers in econometrics. New York: Academic; 1974. p. $105-42$.

29. Train K. Discrete choice methods with simulation. 2nd ed. Cambridge: Cambridge University Press; 2009

30. Hole A, Kolstad J. Mixed logit estimation of willingness to pay distributions: a comparison of models in preference and WTP space using data from a health-related choice experiment. Empir Econ. 2011;42(2):445-69.

31. Hole A. Fitting mixed logit models by using maximum simulated likelihood. Stata Journal. 2007;7(3):388-401.

32. Ministry of Medical Services, Ministry of Public Health and Sanitation. Training procedure guidelines. Nairobi: Ministry of Medical Services, Ministry of Public Health and Sanitation; 2011.

33. Honda A, Vio F. Incentives for non-physician health professionals to work in the rural and remote areas of Mozambique-a discrete choice experiment for eliciting job preferences 2015. Hum Resour Health. 2015;13:23.

34. Clinical Officers Council. Strategic plan for years 2011 to 2016. Nairobi: COC; 2011. [http://clinicalofficerscouncil.org/resources/STRATEGIC_PLAN_FOR_ COC.pdf] (Accessed July 2 2015).

35. Manongi RN, Marchant TC, Bygbjerg IC. Improving motivation among primary health care workers in Tanzania: a health worker perspective. Hum Resour Health. 2006:4:6.

36. Manafa O, McAuliffe E, Maseko F, Bowie C, MacLachlan M, Normand C. Retention of health workers in Malawi: perspectives of health workers and district management. Hum Resour Health. 2009;7:65.

37. Willis-Shattuck M, Bidwell P, Thomas S, Wyness L, Blaauw D, Ditlopo P. Motivation and retention of health workers in developing countries: a systematic review. BMC Health Serv Res. 2008;8:247.

38. Kruk ME, Johnson JC, Gyakobo M, Agyei-Baffour P, Asabir K, Kotha SR, et al. Rural practice preferences among medical students in Ghana: a discrete choice experiment. Bull World Health Organ. 2010;88:333-41.

39. Hanson K, Jack W. Health worker preferences for job attributes in Ethiopia: results from a discrete choice experiment. Washington: Working paper, Georgetown University; 2008. [http://www9.georgetown.edu/faculty/wgj/ papers/Hanson-Jack-04-23-08.pdf] (Accessed July 2 2015).

40. Mathauer I, Imhoff I. Health worker motivation in Africa: the role of nonfinancial incentives and human resource management tools. Hum Resour Health. 2006;4:24.

41. McCoy D, Bennett S, Witter S, Pond B, Baker B, Gow J, et al. Salaries and incomes of health workers in sub-Saharan Africa. Lancet. 2008;371:675-81.

42. Kolstad JR. How to make rural jobs more attractive to health workers. Findings from a discrete choice experiment in Tanzania. Health Econ. 2011; 20:196-211.

43. Rockers $P$, Jaskiewicz $W$, Kruk $M$, Phathammavong $O$, Vanghonevilay $P$, Paphassarang $C$, et al. Differences in preferences for rural job postings between nursing students and practicing nurses: evidence from a discrete choice experiment in Lao People's Democratic Republic. Hum Resour Health. 2013;11:22.

44. Araújo E, Maeda A. How to recruit and retain health workers in rural and remote areas in developing countries: a guidance note. Health, nutrition and population (HNP) discussion paper. Washington, D.C: World Bank; 2013.

45. Ministry of Health: eHealth Kenya facilities. Nairobi: Ministry of Health. 2013. [http://www.ehealth.or.ke/facilities/default.aspx] (Accessed July 2 2015).

46. Hole A. A comparison of approaches to estimating confidence intervals for willingness to pay measures. Health Econ. 2007;16:827-40.

\section{Submit your next manuscript to BioMed Central and we will help you at every step:}

- We accept pre-submission inquiries

- Our selector tool helps you to find the most relevant journal

- We provide round the clock customer support

- Convenient online submission

- Thorough peer review

- Inclusion in PubMed and all major indexing services

- Maximum visibility for your research

Submit your manuscript at www.biomedcentral.com/submit 